\title{
CHAVE DE IDENTIFICAÇÃO: ANFÍBIOS ANUROS DA VERTENTE DE JUNDIAÍ DA SERRA DO JAPI, ESTADO DE SÃO PAULO
}

\author{
Ricardo da Silva Ribeiro ${ }^{1^{*}}$, Gabriel Toselli Barbosa Tabosa do Egito ${ }^{2}$ \& Célio Fernando Baptista Haddad ${ }^{1}$
}

Biota Neotropica v5 (n2) - http://www.biotaneotropica.org.br/v5n2/pt/abstract?identification-key+bn03005022005

\author{
Recebido em 02/05/05. \\ Versão reformulada recebida em 24/08/05. \\ Publicado em 10/10/05
}
1. Laboratório de Herpetologia, Depto. de Zoologia, Instituto de Biociências, Caixa Postal 199, UNESP, Av. 24-A, 1515, Jd. Bela Vista, Rio Claro (SP) 13506-900.
* Autor-correspondente. E-mail: rribeiro@rc.unesp.br
2. Laboratório de Citogenética Animal, Depto. de Biologia Celular, Instituto de Biologia, Caixa Postal 6109, UNICAMP, Cidade Universitária “Zeferino Vaz”, Distrito de Barão Geraldo, Campinas (SP) 13084-971.

\begin{abstract}
The Área de Proteção Ambiental Jundiaí is an important environmental reserve located at a mountain range between two metropolis of São Paulo state: São Paulo and Campinas. It is an area of great interest for scientific research and conservation, being a region of transition between two ecosystems (Atlantic Ombrophilous Forest and Atlantic Semideciduous Seasonal Forest), and sheltering a great species diversity. Although studied since the middle 80's there is no identification key available for the anuran species of the area until this moment. Thirty one anuran species from six different families have already been recorded at the side of the mountain range directed towards Jundiaí. We present here an illustrated dichotomous identification key for anurans of this area.
\end{abstract}

Key words: Identification key, taxonomy, São Paulo, Atlantic Forest, amphibians, anurans.

\section{Resumo}

A Área de Proteção Ambiental Jundiaí, na Serra do Japi, é uma importante reserva ambiental situada entre duas metrópoles - São Paulo e Campinas - do estado de São Paulo. Trata-se de uma área de grande interesse para a conservação e a pesquisa científica, por se tratar de uma região de transição entre a Mata Atlântica Ombrófila e a Mata Atlântica Estacional Semidecídua do Planalto Ocidental Paulista, abrigando uma grande diversidade de espécies representativas de ambos os ecossistemas. Apesar de ser objeto de estudos desde meados da década de 80, não há nenhuma chave de identificação das espécies da anurofauna disponível para a área até o momento. Trinta e uma espécies de anuros de seis famílias diferentes já foram registradas na vertente do Município de Jundiaí. Apresentamos aqui uma chave dicotômica ilustrada de identificação para os anfíbios anuros da vertente do rio Jundiaí na Serra do Japi.

Palavras-chave: Chave de identificação, taxonomia, São Paulo, Mata Atlântica, anfíbios, anuros.

http://www.biotaneotropica.org.br 


\section{Introdução}

Os anfíbios anuros, em geral, apresentam plano de corpo pouco variável, o que em muitos casos dificulta a identificação por meio de uma análise superficial. Algumas espécies próximas, como Eleutherodactylus guentheri e $E$. binotatus (Leptodactylidae), exigem um exame mais atento, por exemplo, nos tamanhos relativos dos artelhos.

AÁrea de Proteção Ambiental (APA) Jundiaí, na Serra do Japi, é uma importante reserva ambiental situada entre os municípios de Jundiaí, Cabreúva e Cajamar, no estado de São Paulo. Por se tratar de uma área de transição entre a floresta ombrófila e as florestas estacionais semidecíduas do Planalto Paulista, ela abriga uma grande diversidade de espécies representantes desses dois grandes ecossistemas. Trinta e um anfíbios de seis famílias, entre as 33 que formam a Ordem Anura (Frost 2004), podem ser encontrados nessa reserva.

Apesar de sua anurofauna ter sido objeto de estudos a partir de meados dos anos 80 (e. g. Andrade 1987, Cardoso et al. 1989, Haddad 1991, Haddad \& Sazima 1992, Giaretta et al. 1997), não há nenhuma chave de identificação de espécies disponível para a área até o momento. O presente trabalho, uma adaptação de uma chave eletrônica de múltipla entrada (Ribeiro et al. 2005), visa facilitar a identificação desses animais tanto por estudantes que estão se iniciando no assunto, quanto por herpetólogos já formados, como também por pesquisadores não-especialistas no grupo, facilitando assim estudos ecológicos e/ou evolutivos sobre os anfíbios anuros brasileiros, bem como eventuais levantamentos faunísticos e estudos de impacto ambiental próximos à Serra do Japi. Afinal, o Brasil apresenta a maior riqueza e a segunda maior diversidade ecológica de espécies de anfíbios do mundo (Mittermeier et al. 1997), com 775 espécies conhecidas, sendo 747 pertencentes à Ordem Anura (SBH 2005); e ainda muito para ser estudado.

\section{Material e Métodos}

A lista de espécies para a área foi baseada em Haddad \& Sazima (1992), sendo alguns acréscimos feitos por meio de observações pessoais e de terceiros em visitas à área, entre 1999 e 2005. Para a elaboração da lista de espécies não nos restringimos às localidades citadas no texto de Haddad e Sazima (1992) (represa do DAE e Ermida). Consideramos a vertente de Jundiaí da Serra do Japi como um todo, uma vez que, desde a publicação do referido estudo, diversos dados novos foram obtidos em outras áreas da serra. Assim sendo, o presente estudo não se constitui em uma simples atualização do trabalho de Haddad \& Sazima (1992), mas uma ampliação da lista, que passa a abranger toda a área da serra sob jurisdição da municipalidade de Jundiaí. Os textos sobre as espécies, constituindo uma lista comentada, também não se constituem em uma mera repetição do referido trabalho do início da década de 90, pois se restringem a informações de biologia básica das espécies não citadas ou não devidamente detalhadas no referido trabalho, sendo algumas indisponíveis na época do primeiro estudo. Além disso, os textos reúnem ou acrescentam novas informações sobre novas distribuições geográficas para as espécies. A chave foi elaborada a partir do exame de topótipos (no caso de Hylodes ornatus) e de material coletado na Serra do Japi e seu entorno e depositado na coleção do Museu de História Natural da Universidade Estadual de Campinas (ZUEC) e na coleção “Célio F. B. Haddad” (CFBH) do Departamento de Zoologia da Unesp, Campus de Rio Claro. Os caracteres utilizados na construção da chave são próprios ou modificados de Heyer et al. (1990) e Kwet \& Di-Bernardo (1999).

\section{Resultados e Discussão}

Haddad \& Sazima (1992) relatam a ocorrência de 24 espécies na Área de Proteção Ambiental Jundiaí, na Serra do Japi, às quais acrescentamos Dendropsophus microps, D. minutus, D. sanborni, Hypsiboas albopunctatus, Scinax eurydice, Odontophrynus americanus e Elachistocleis cf. ovalis, cujas presenças foram constatadas na serra nos últimos anos. Assim sendo, até o momento foi constatada a ocorrência de 31 espécies de seis famílias diferentes de anfíbios anuros na reserva, sendo as famílias Hylidae e Leptodactylidae as mais abundantes, com respectivamente 16 e 10 espécies.

\section{Lista comentada de espécies de anfíbios anuros da Área de Proteção Ambiental Jundiaí}

\section{Família Brachycephalidae}

·Brachycephalus ephippium (Spix, 1824)

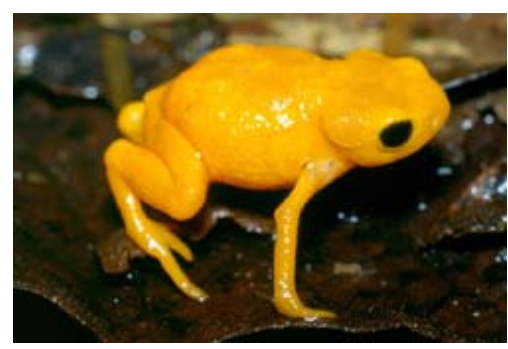

Figura 1 - Família Brachycephalidae: Brachycephalus ephippium.

Sapinho amarelo-dourado (Figura 1), com aproximadamente $20 \mathrm{~mm}$ de comprimento rostro-cloacal (CRC). Ocorre nos estados de São Paulo, Minas Gerais e Rio de Janeiro (obs. pess.). A ocorrência da espécie no estado 
da Bahia (Frost 2004) nunca foi confirmada e provavelmente trata-se de erro de procedência. Uma espécie ainda não descrita que ocorre no Espírito Santo (Frost 2004) era anteriormente confundida com esta espécie. As populações que ocorrem no Paraná (Frost 2004), antes atribuídas a esta espécie, pertencem às espécies Brachycephalus pernix (Pombal et al. 1998), B. bruneus e B. izecksohni (Ribeiro et al. 2005), bem como a espécies novas ainda não descritas. Habita matas de encosta em altitudes elevadas, acima de $750 \mathrm{~m}$, sendo normalmente encontrada em dias úmidos em manchas populacionais, em altas densidades. Esse padrão de distribuição, o tamanho reduzido dos indivíduos e o fato de possuirem mobilidade restrita contribuem para a ocorrência de espécies crípticas sob esse nome. Assim sendo, é possível que o nome Brachycephalus ephippium se aplique a algumas populações da Serra do Mar, devendo ser atribuído um novo nome para as populações da Serra da Mantiqueira.

\section{Família Bufonidae}

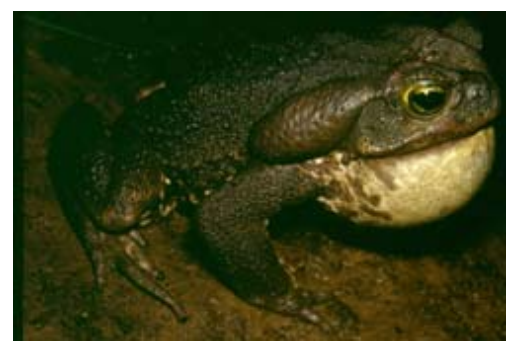

Figura 2 - Família Bufonidae: a) Bufo ictericus.

\section{·Bufo ictericus Spix, 1824}

É um sapo grande (Figura 2a), com adultos com 100 a 170 mm de CRC, que possui dimorfismo sexual de coloração pronunciado, bem como de tamanho, com as fêmeas sendo maiores que os machos. As fêmeas possuem coloração pardo-clara, com uma grande mancha dorsal enegrecida, dividida ao meio por uma faixa clara; os machos possuem coloração pardo-amarelada uniforme. As glândulas parotóides dos indivíduos dessa espécie são grandes (normalmente superior a 30\% do CRC). Seu canto de anúncio é semelhante ao de Bufo ornatus, sendo mais grave e com a emissão de um menor número de notas por unidade de tempo. Sua estação reprodutiva e seus sítios de vocalização e oviposição sobrepõem-se aos de B. ornatus. Devido a esses fatores, já foram observados acasalamentos heteroespecíficos entre essas duas espécies, particularmente entre fêmeas de $B$. ictericus e machos de $B$. ornatus, bem como hibridação com a formação de indivíduos inviáveis (Haddad et al. 1990). É uma espécie de distribuição ampla, ocorrendo na Mata Atlântica do Sudeste e Sul do Brasil, além da província de Misiones (Argentina) e leste do
Paraguai. Recentemente foi encontrado um exemplar no cerrado de Goiás (Souza et al. 2001), sendo essa ocorrência inusitada para esta espécie.

·Bufo ornatus Spix, 1824

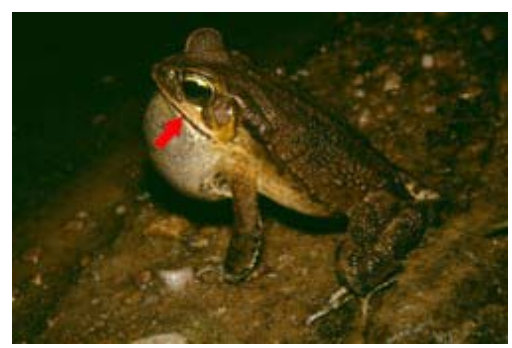

Figura 2 - Família Bufonidae: b) B. ornatus: note a coloração creme sob o olho (indicada pela seta), que a distingue de B. ictericus.

A denominação Bufo ornatus, aplicável para esta população anteriormente denominada como Bufo crucifer, foi revalidada por Baldissera Jr. et al. (2004). É um sapo médio a grande (Figura 2b), com adultos medindo entre 55 e $95 \mathrm{~mm}$ de CRC. Ao contrário de Bufo ictericus, esta espécie não apresenta dimorfismo sexual de coloração, apenas de tamanho, com as fêmeas sendo maiores que os machos. Suas glândulas parotóides são relativamente pequenas (menos que 20\% do CRC). Seu canto é semelhante ao de $B$. ictericus, sendo mais agudo e com emissão de um maior número de notas por unidade de tempo. Seus ambientes de reprodução e sua estação reprodutiva sobrepõem-se aos de $B$. ictericus. Esse conjunto de fatores contribui para a ocorrência de acasalamentos heteroespecíficos entre essas duas espécies, fato este já observado na área, especialmente entre fêmeas de $B$. ictericus e machos de $B$. ornatus, bem como na formação de híbridos inviáveis (Haddad et al. 1990). Ocorre no Sul e Sudeste do Brasil, desde o sul do estado do Espírito Santo até o norte do estado do Paraná, e nas províncias de Misiones e Corrientes, na Argentina (Baldissera Jr. et al. 2004).

\section{Família Centrolenidae}

·Hyalinobatrachium eurygnathum (A. Lutz, 1925)

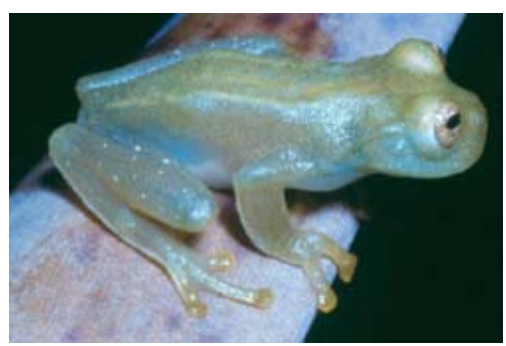

Figura 3 - Família Centrolenidae: Hyalinobatrachium eurygnathum. 
Denominada como Centrolenella cf. eurygnatha no trabalho de Haddad \& Sazima (1992), é uma perereca verde pequena (Figura 3 ), com cerca de $20 \mathrm{~mm}$ de CRC, que deposita seus ovos em folhas pendentes sobre córregos no interior da mata. Possui o ventre transparente. Esta espécie vem sofrendo forte redução populacional e há cerca de vinte anos não mais tem sido encontrada na Serra do Japi, tendo também desaparecido de diversas outras localidades de altitudes elevadas no Sudeste do Brasil, até mesmo de algumas localidades aparentemente não alteradas por ação humana. Recentemente foi registrado um exemplar na Bahia, sendo esta a primeira ocorrência da espécie fora da região Sudeste e a primeira da família no Nordeste do país (Freitas et al. 2004).

\section{Família Hylidae}

As espécies anteriormente pertencentes ao gênero Hyla foram recentemente realocadas por Faivovich et al. (2005) em outros gêneros, os quais, em sua maioria, não possuem sinapomorfias morfológicas conhecidas para indivíduos pós-metamórficos. Sempre que tal característica existir estará indicada no texto da primeira espécie tratada para o gênero.

\section{·Aplastodiscus arildae (Cruz \& Peixoto, 1987)}

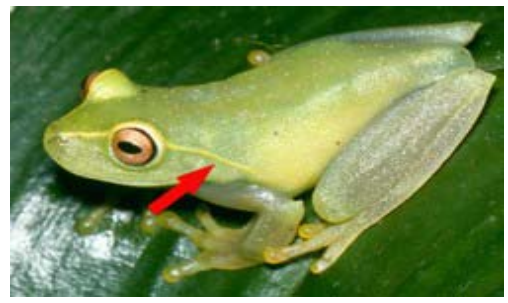

Figura 4 - Família Hylidae: a) Aplastodiscus arildae: note a linha pós-orbital branca (indicada pela seta).

É uma perereca verde (Figura 4a) de porte médio (35 a 45 mm de CRC), cuja distribuição é restrita às Serras da Mantiqueira e do Mar, em altitudes entre 800 e 1500 m. Seu dorso é verde com muitos pontos brancos e alguns marrons. Seus ossos são verdes. É uma espécie de hábitos noturnos e florestais, que se reproduz às margens dos riachos de montanha, depositando os ovos em ninhos aquáticos subterrâneos, escavados pelos machos. Uma possível característica distintiva para o gênero é o fato dos tubérculos metatarsais e metacarpais se apresentarem relativamente bem desenvolvidos (Faivovich et al. 2005), característica esta pouco útil para diagnose imediata por parte de nãoespecialistas, uma vez que exigiria a comparação do tamanho dos tubérculos de indivíduos desta espécie com os de representantes de outros gêneros.
-Aplastodiscus leucopygius (Cruz \& Peixoto, 1985)

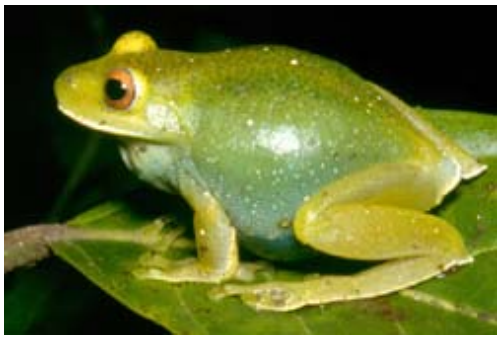

Figura 4 - Família Hylidae: b) A. leucopygius.

É uma perereca verde de porte médio (35 a 45 mm de CRC) conhecida nas Serras do Mar e da Mantiqueira, nos estados do Rio de Janeiro e de São Paulo. Seu dorso é verde com muitas pintas marrons e algumas brancas (Figura 4b). Apresenta o lábio inferior e apêndices calcâneos brancos. Possui um flap cloacal também branco (daí o seu nome). Seus ossos são verdes. Sua desova é aquática, depositada em tocas subterrâneas, que são escavadas pelos machos na lama das margens de poças temporárias e riachos.

\section{·Bokermannohyla luctuosa (Pombal \& Haddad, 1993)}

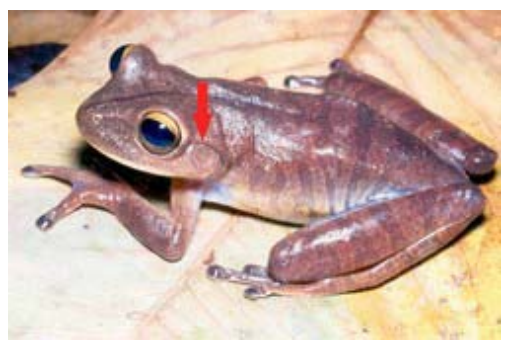

Figura 4 - Família Hylidae: c) Bokermannohyla. luctuosa: note o tímpano parcialmente coberto por uma prega dérmica (seta).

Trata-se da espécie denominada como “Hyla sp. (aff. circumdata)” no capítulo de Haddad \& Sazima (1992). Espécie descrita a partir de exemplares coletados na Serra do Japi (Pombal \& Haddad 1993), foi registrada também no Parque Nacional do Itatiaia, no estado do Rio de Janeiro (Napoli 2000). É uma perereca de grande porte, com cerca de 60 mm de CRC (Figura 4c). Não existem quaisquer outros estudos sobre esta espécie.

\section{·Dendropsophus microps (Peters, 1872)}

É uma perereca de porte pequeno (20 a $30 \mathrm{~mm}$ de CRC), de coloração castanha, alaranjada, bege ou castanhoavermelhada, com padrão que se assemelha a casca de árvore ou liquens. A face inferior de seu pé e membros posteriores 


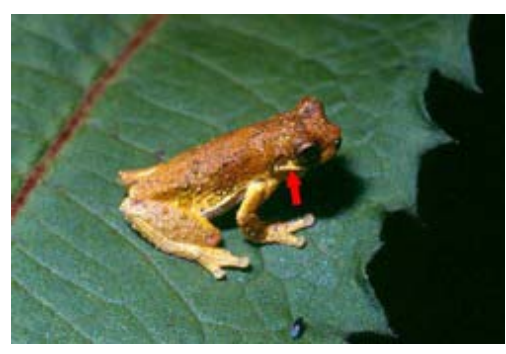

Figura 4 - Família Hylidae: d) Dendropsophus microps: note a região clara abaixo do tímpano (seta).

é alaranjada ou vermelha. Possuem uma área clara (Figura 4d) sob o olho e o tímpano. Os machos, quando vocalizam à noite, possuem coloração dorsal amarela uniforme. Ocorre em interior e borda de florestas, na Mata Atlântica do Sudeste e Sul do Brasil (Frost, 2004).

\section{·Dendropsophus minutus (Peters, 1872)}

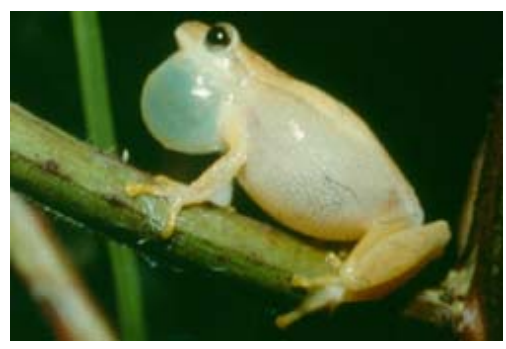

Figura 4 - Família Hylidae: e) D. minutus; H. leucopygia.

É uma perereca pequena (Figura 4e), com 20 a 25 mm de CRC, de coloração castanha, castanho-alaranjada ou bege, com uma mancha mais escura no dorso, inteira ou dividida, que lembra a forma de uma ampulheta. A face posterior de suas coxas é avermelhada ou alaranjada. Possuem um extenso repertório vocal, com cantos formados por várias notas. Costumam cantar em grandes coros e é comum utilizarem-se da estratégia de macho-satélite para se acasalarem (Haddad 1991). Sua área de distribuição é ampla, ocorrendo desde áreas de baixada até $2000 \mathrm{~m}$ de altitude, desde as áreas baixas a leste dos Andes da Colômbia, passando pela Venezuela e Trinidad e, indo em direção ao sul, através do Equador, Peru e Brasil até a Bolívia, Uruguai e Argentina. É possível que haja mais de uma espécie sendo confundida sob este nome nesta extensa área de ocorrência, uma vez que há diferenças morfológicas significativas entre os indivíduos das populações do Norte e do centro-sul do continente.

\section{•Dendropsophus sanborni (Schmidt, 1944)}

É uma perereca pequena (Figura 4f), com 20 a 25 mm, de coloração castanha, alaranjada ou bege, com pequenos

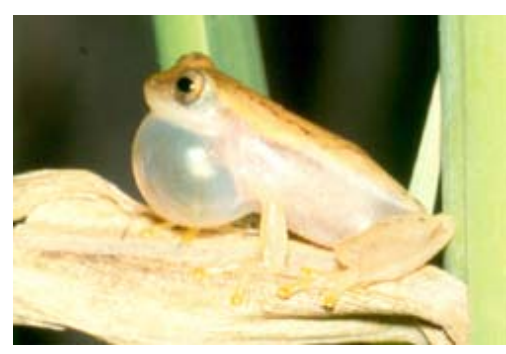

Figura 4 - Família Hylidae: f) D. sanborni.

pontos escuros arranjados longitudinalmente. Ocorre no Sul e Sudeste do Brasil, sul do Paraguai, Uruguai e leste e centro da Argentina (nas províncias de Corrientes e Buenos Aires). Além disso, localizamos na Coleção CFBH um exemplar coletado no Mato Grosso, o que torna provável sua ocorrência em outras áreas do Centro-Oeste brasileiro.

\section{·Hypsiboas albopunctatus (Spix, 1824)}

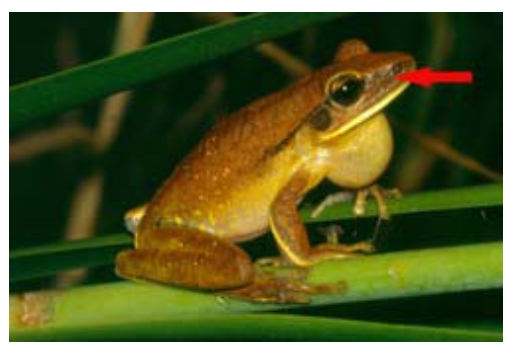

Figura 4 - Família Hylidae: g) Hypsiboas albopunctatus: note a "máscara” de coloração escura (seta).

É uma perereca (Figura 4g) de porte médio a grande (30 a 65 mm de CRC), que possui ampla distribuição no Brasil, sendo encontrada no Planalto Central, nos estados do Sul e em quase todos os estados do Sudeste, e também no estado de Rondônia (Eterovick \& Sazima, 2004). Ocorre também no nordeste da Argentina (na província de Corrientes), no leste da Bolívia (no departamento de Santa Cruz) e no leste do Paraguai e no Uruguai. Seu colorido vai do amarelo ao marrom-claro. É uma espécie típica de Cerrado, ocorrendo em áreas abertas na Serra do Japi. Como característica distintiva possui pintas na face posterior das coxas. Essas pintas são amarelas em vida, mas foram descritas como se fossem brancas pelo fato dos autores se basearem em exemplares preservados; daí vem o termo albopunctata. Tanto machos quanto fêmeas possuem prépólex (Figura 5a), mas este às vezes acha-se pouco distinto nas fêmeas. Seu focinho possui uma faixa lateral escura, sendo a região abaixo dessa faixa - a “máscara” - de coloração marrom-escura a negra.

·Hypsiboas bischoffi (Boulenger, 1887) 


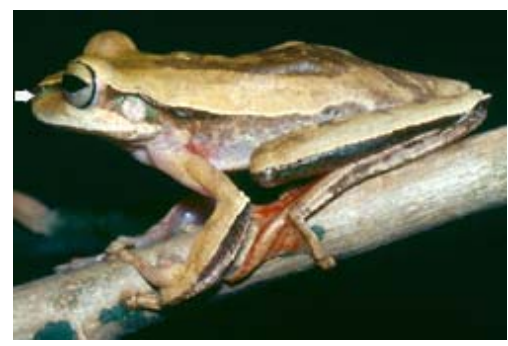

Figura 4 - Família Hylidae: h) H. bischoffi: note a "máscara” de coloração verde (seta).

Pode ser encontrada em toda a porção meridional da Mata Atlântica, desde o Rio de Janeiro até o Rio Grande do Sul. É uma espécie de hábitos noturnos e tolerante ao desmatamento, ocorrendo mesmo em borda de mata e ambientes antropizados. Alcança um porte médio a grande (40 a 65 mm de CRC) e apresenta coloração dorsal alaranjada, castanha ou bege, geralmente com linhas escuras. Apresenta uma faixa lateral escura, que se estende do focinho até a região mediana do tronco, com uma estreita borda superior esbranquiçada. Na região do focinho, abaixo da faixa, apresenta uma “máscara” verde (Figura 4h). As laterais das pernas e dos pés possuem uma faixa longitudinal marrom e/ ou verde-escura. A população em questão pertence à subespécie $H$. $b$. multilineata, que pode ser distinguida de H. b. bischoffi (Figura 4h) pelo padrão dorsal (esta última subespécie possui manchas irregulares no dorso, ao invés de linhas escuras).

\section{·Hypsiboas faber (Wied-Neuwied, 1821)}

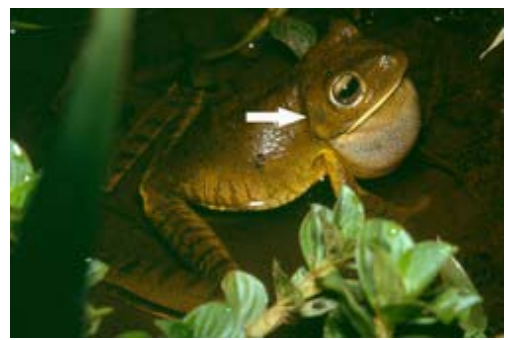

Figura 4 -Família Hylidae: i) H. faber: note o tímpano totalmente visível (seta).

É encontrada no leste do Brasil, principalmente entre o Sudeste e o Sul, mas também no estado da Bahia, de regiões de baixadas às serras, na Mata Atlântica e marginalmente no Cerrado. Também ocorre no sudeste do Paraguai e na província de Misiones, na Argentina. Alcança um grande tamanho, com 80 a $100 \mathrm{~mm}$ de CRC, e possui o dorso alaranjado, bege ou castanho-escuro (Figura 4i). A maioria dos indivíduos possui uma linha escura que se estende do extremo do focinho à região mediana do dorso. Os girinos podem adotar hábitos canibalísticos (Bernarde \& Machado 1999) e sofrem metamorfose no verão seguinte ao nascimento, após um longo período vivendo sobre o fundo de lagoas e represas (Kwet \& Di-Bernardo 1999).

\section{·Hypsiboas prasinus (Burmeister, 1856) (Figura 4j)}

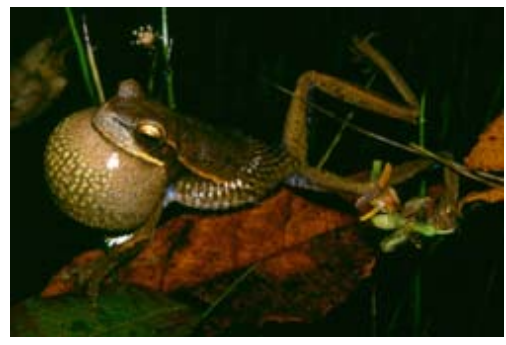

Figura 4 - Família Hylidae: j) H. prasinus.

É uma espécie de porte médio (40 a 50 mm de CRC). Seu pré-pólex (Figura 5a) é bem distinto, tanto em machos quanto em fêmeas, sendo um pouco maior naqueles. Ocorre no Sudeste do Brasil (estados de Minas Gerais, Rio de Janeiro e São Paulo) e no estado do Rio Grande do Sul (Kwet \& Miranda 2001), em altitudes moderadas. Além disso, localizamos três exemplares coletados em Santa Catarina, estando um exemplar depositado na Coleção CFBH e outros dois na coleção do Museu Nacional (MNRJ), o que torna provável sua ocorrência no estado do Paraná.

\section{·Phasmahyla cochranae (Bokermann, 1966)}

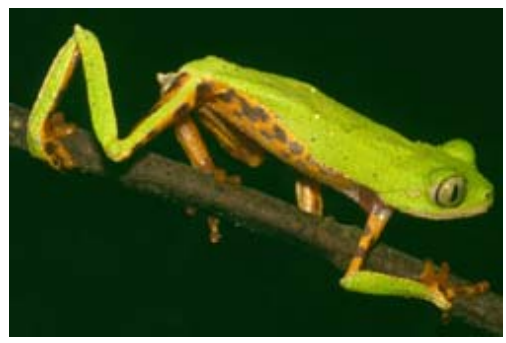

Figura 4 - Família Hylidae: k) Phasmahyla cochranae: note a coloração característica da lateral do corpo e das pernas.

É uma perereca arborícola de porte médio (entre 30 e $40 \mathrm{~mm}$ de CRC). As pupilas das espécies pertencentes à subfamília deste gênero (Phyllomedusinae) são verticalmente elípticas, a única sinapomorfia morfológica observável em indivíduos pós-metarmorficos pertencentes a esta subfamília. Possuem manchas castanhas contornadas de amarelo nas laterais do corpo e das pernas (Figura 4k). 
·Phyllomedusa burmeisteri Boulenger, 1882

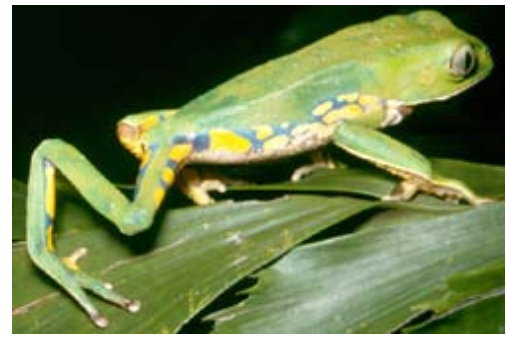

Figura 4 - Família Hylidae: l) Phyllomedusa burmeisteri: note a coloração característica da lateral do corpo e das pernas.

É uma perereca arborícola de porte médio a grande (entre 50 e $60 \mathrm{~mm}$ de CRC). Ocorre em grande parte do Sudeste do Brasil e no estado da Bahia. Assim como a espécie anterior, $P$. burmeisteri também é um representante da subfamília Phyllomedusinae. Possuem manchas amarelas contornadas de azul nas laterais do corpo e das pernas (Figura 4l). Essa espécie dobra as folhas das árvores, colando-as com cápsulas ovígeras vazias, formando um funil onde depositam sua desova, que fica pendente sobre poças, mas também em remansos de riachos (obs. pess.), onde os girinos caem após a eclosão e completam seu desenvolvimento.

\section{·Scinax eurydice (Bokermann, 1968)}

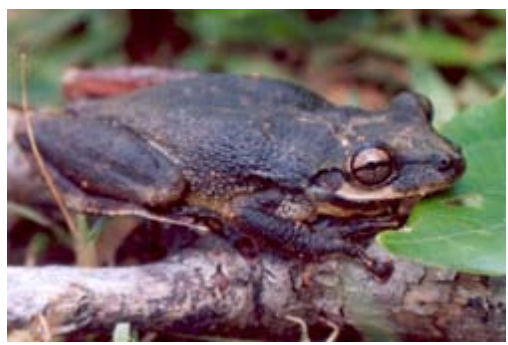

Figura 4 - Família Hylidae: m) Scinax eurydice: coloração diurna; durante a noite esta perereca possui coloração dorsal clara, que evidencia as faixas escuras características, atrás do olho.

Ocorre do norte da Bahia (obs. pess.) até São Paulo. É uma perereca (Figura 4m) de porte mediano (35 a 50 mm de CRC) que possui coloração dorsal bege, com manchas irregulares castanhas. Possui duas faixas dorsais que se estendem da região posterior de cada olho até o meio do dorso. Uma característica distintiva para esse gênero é que uma articulação em seu primeiro artelho permite que este se dobre para trás (Jungfer 1987, Figura 6).
-Scinax fuscovarius (Lutz, 1925)

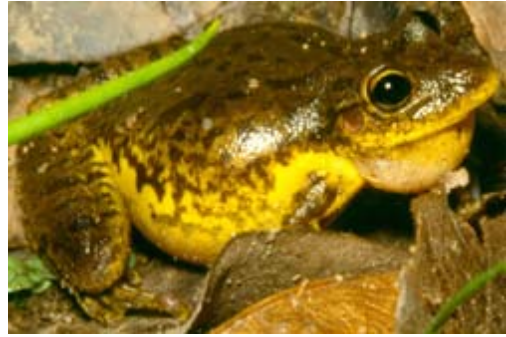

Figura 4 - Família Hylidae: n) S. fuscovarius.

Provavelmente há mais de uma espécie sob essa denominação ao longo de sua ampla distribuição, que se estende pelo estado de Goiás, Nordeste (Eterovick \& Sazima, 2004), Sudeste e Sul do Brasil, pelo Uruguai e pelo norte da Argentina, Paraguai e Bolívia, desde 150 até 1800 m de altitude. Possui porte mediano a grande (40 a $60 \mathrm{~mm}$ de CRC) e coloração dorsal castanho-escura ou castanho-acinzentada (Figura 4n), com duas manchas interoculares pouco distintas e padrão variável de linhas escuras e manchas. A superfície interna de suas coxas e sua cintura têm colorido amarelo-vivo e negro. É uma espécie comum, que se adaptou muito bem a ambientes antropizados e é comumente encontrada em banheiros, ralos e instalações hidráulicas, o que lhe dá o nome popular de perereca-do-banheiro. Devido ao seu canto, que lembra um ruído de raspagem, é também conhecida como raspa-cuia.

\section{·Scinax hayii (Barbour, 1909)}

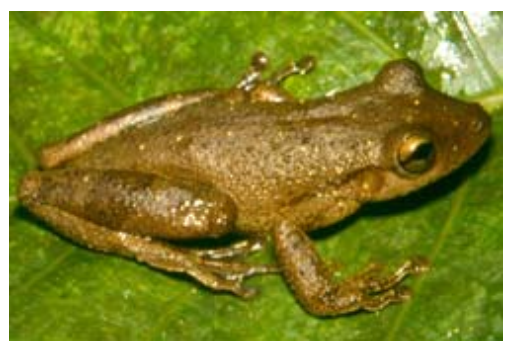

Figura 4 - Família Hylidae: o) S. hayii.

Pode haver mais de uma espécie sob esse nome ao longo de sua distribuição pelo Sudeste e Sul do Brasil, do Espírito Santo a Santa Catarina, na Serra do Mar e da Mantiqueira. Sua coloração apresenta grande variabilidade. É uma perereca de porte médio (Figura 4o), com 35 a 45 mm de CRC. 
· Scinax hiemalis (Haddad \& Pombal, 1987)

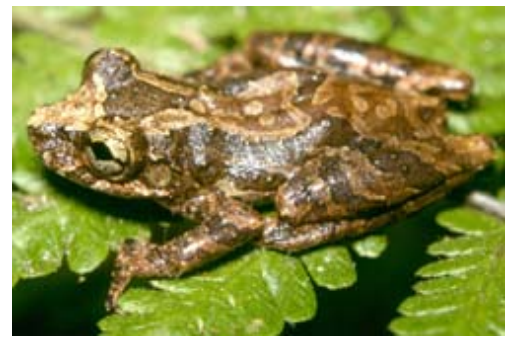

Figura 4 - Família Hylidae: p) S. hiemalis.

É uma perereca de porte pequeno a médio (Figura 4p), com 25 a 35 mm de CRC, que ocorre em matas de planalto nas regiões de Campinas e Botucatu, no estado de São Paulo. Seu nome se deve ao seu comportamento reprodutivo ser restrito ao inverno (hiemalis = invernal). Uma característica distintiva para esse gênero é que uma articulação em seu primeiro artelho permite que este se dobre para trás (Jungfer 1987, Figura 6).
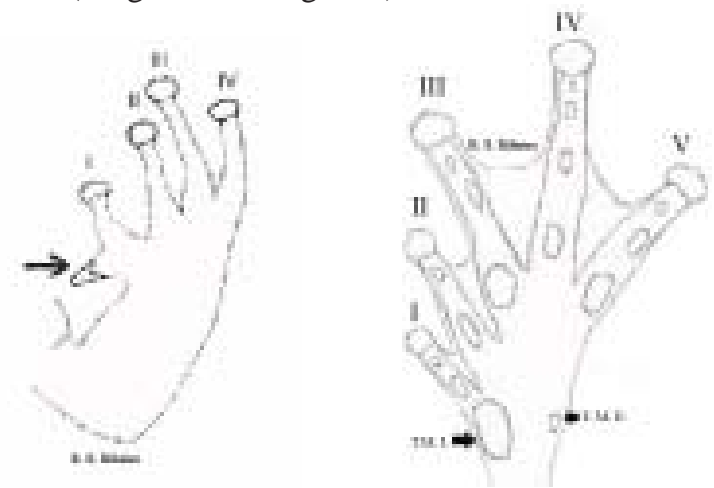

Figura 5 - a) Vista dorsal do membro anterior direito de um macho de Hyla com pré-pólex bem desenvolvido. A seta indica o pré-pólex que, nas fêmeas e em determinadas espécies, pode ser menos desenvolvido. A área mais escura do pré-pólex corresponde ao espinho. Note também os discos adesivos nas extremidades dos dedos, que estão numerados em algarismos romanos; b) Vista ventral do pé esquerdo de um anuro. Note as membranas interdigitais e os discos adesivos nas extremidades dos artelhos, que estão numerados em algarismos romanos. TMI = tubérculo metatarsal interno; TME = tubérculo metatarsal externo.

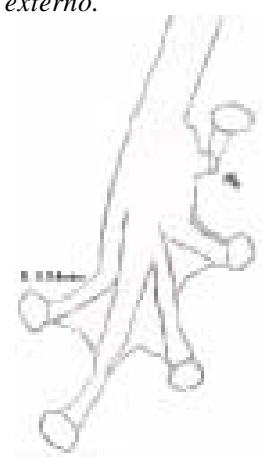

Figura 6 - Vista dorsal do pé direito de uma perereca do gênero Scinax. A articulação do artelho I (indicada pela seta), presente nas espécies deste gênero, permite que este se dobre para trás (desenhado a partir de uma foto em Jungfer 1987).

\section{Família Leptodactylidae}

-Crossodactylus sp. (Figura 7a)

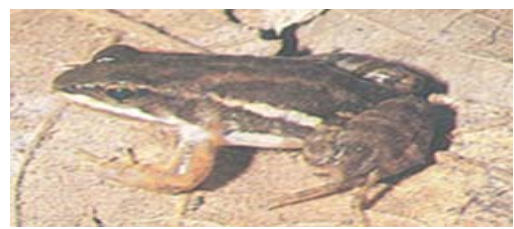

Figura 7 - Família Leptodactylidae: a) Crossodactylus $s p$.

É uma rãzinha (cerca de $20 \mathrm{~mm}$ de CRC) que apresenta hábitos diurnos. Este é um gênero que requer revisão de suas espécies, por isso achamos conveniente não atribuirmos por hora uma denominação a esta população. Membros desse gênero costumam ter uma distribuição restrita, às vezes limitada a uma única bacia hidrográfica. Esta espécie, relacionada a Crossodactylus dispar, pode ser encontrada em alguns locais da Serra do Mar e na cidade de São Paulo.

\section{•Eleutherodactylus binotatus (Spix, 1824)}

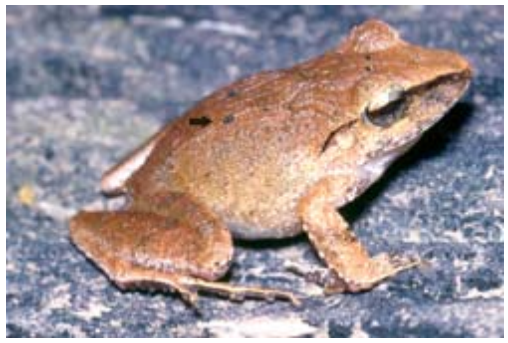

Figura 7 - Família Leptodactylidae: b) Eleutherodactylus binotatus: note o par de pontos negros (indicado pela seta), que caracteriza a espécie.

Distribui-se desde a Bahia até o Sudeste brasileiro, sendo uma espécie estritamente florestal. Pode haver mais de uma espécie sendo tratada sob este nome. É uma rã de porte médio a grande (45 a $65 \mathrm{~mm}$ de CRC). Freqüentemente, possui um par de pequenos pontos negros no meio do dorso, que tem coloração bege, cinza ou parda (Figura 7b).

\section{·Eleutherodactylus guentheri (Steindachner, 1864)}

É uma espécie estritamente florestal, podendo ser encontrada no Sudeste e Sul do Brasil, do Espírito Santo ao Rio Grande do Sul, e na província argentina de Misiones além de, presumivelmente, em áreas adjacentes no Paraguai. 


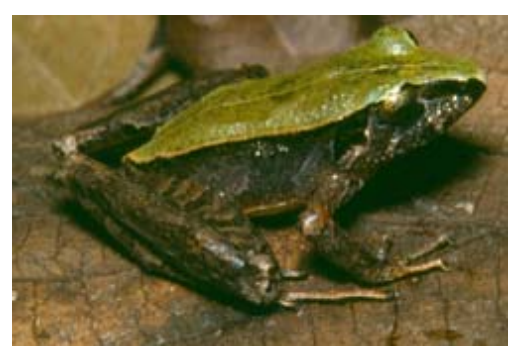

Figura 7 - Família Leptodactylidae: c) E. guentheri: a coloração da foto não é a padrão para a espécie.

É uma espécie de porte pequeno a médio (25 a $40 \mathrm{~mm}$ ). Apresenta grande variabilidade em diversos caracteres morfológicos e também na vocalização de anúncio ao longo de sua área de distribuição, podendo haver mais de uma espécie sob este nome. A coloração dorsal parda é mais comum que a verde (Figura 7c).

·Eleutherodactylus juipoca Sazima \& Cardoso, 1978

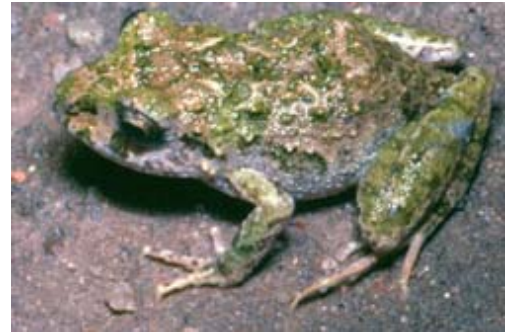

Figura 7 - Família Leptodactylidae: d) E. juipoca: note o dorso granulado.

É uma rã pequena (10 a 25 mm de CRC), encontrada nos planaltos dos estados de São Paulo, Minas Gerais (Eterovick \& Sazima 2004) e Goiás (Bastos \& Pombal-Jr. 2001). Suas características típicas são o focinho truncado e as granulações pelo corpo (Figura 7d).

\section{·Eleutherodactylus parvus (Girard, 1853)}

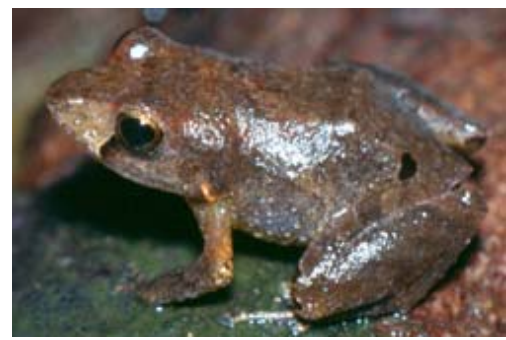

Figura 7 - Família Leptodactylidae: e) E. parvus.
É uma espécie pequena de rã (12 a 23 mm de CRC), de cor cinzenta ou bege (Figura 7e), com uma mancha negra em torno da região cloacal. Apresenta grande variação morfológica. Pode ser encontrada em matas no Sudeste do Brasil.

\section{·Hylodes ornatus (Bokermann, 1967)}

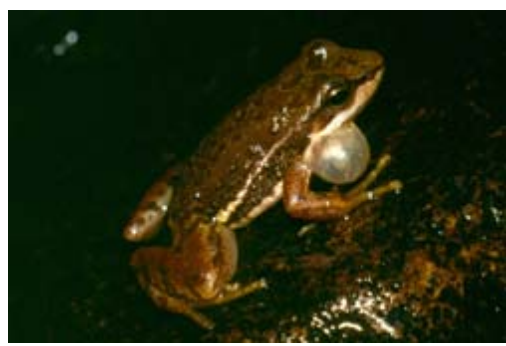

Figura 7 - Família Leptodactylidae: f) Hylodes ornatus.

A vocalização dos indivíduos que ocorrem na Serra do Japi é idêntica à de Hylodes ornatus, o que nos permite dizer que se trata da mesma espécie, anteriormente registrada apenas no Parque Nacional do Itatiaia, no estado do Rio de Janeiro. É uma espécie pequena de rã (25 mm de CRC). A população da Serra do Japi não possui as manchas no dorso, responsáveis pelo nome da espécie e observáveis nos indivíduos da população do Itatiaia (Figura 7f). Assim como outras espécies da subfamília Hylodinae (e. g. Haddad \& Giaretta 1999, Wogel et al. 2004), esta espécie provavelmente deve realizar comunicação visual, uma vez que o ruído de seu ambiente interfere com seu canto.

\section{-Leptodactylus cf. ocellatus}

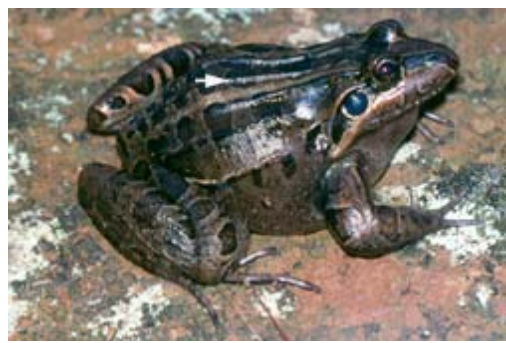

Figura 7 - Família Leptodactylidae: g) Leptodactylus cf. ocellatus: note as pregas dérmicas longitudinais no dorso (seta).

A denominação Leptodactylus ocellatus tem sido usada para várias populações distribuídas pela América do Sul, ao leste dos Andes. O nome se deve às manchas em seu dorso, que lembram ocelos. Possui no mínimo seis pregas dorso-laterais (Figura 7g). No estado de São Paulo há certamente ao menos duas espécies crípticas sob essa nomenclatura, sendo uma na baixada litorânea, de coloração olivácea e outra

http://www.biotaneotropica.org.br 
no Planalto Paulista, de coloração castanho-avermelhada. Apresentam dimorfismo sexual. Os machos são maiores e possuem dois espinhos (negros ou brancos) de origem epidérmica no local do pré-pólex. As fêmeas possuem uma calosidade ao invés de espinhos. Os machos possuem braços robustos, sendo apreciados por diversas pessoas como alimento. São rãs de porte grande a muito grande (entre 90 e 110 mm de CRC) que predam outras espécies de anfíbios. Sua desova é depositada em ninhos de espuma, na superfície da água. As fêmeas apresentam cuidado parental tanto com os ovos como com os girinos. Elas também costumam abrir canais, interligando poças, evitando assim que os girinos fiquem presos e morram por dessecação.

· Odontophrynus americanus (Duméril \& Bibron, 1841)

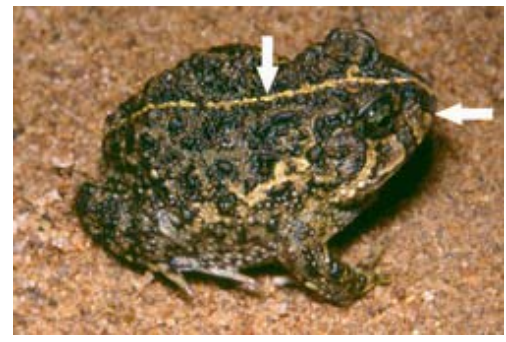

Figura 7 - Família Leptodactylidae: h) Odontophrynus americanus: note a linha clara médio-dorsal e o padrão de barras no lábio superior (setas).

Embora da família das rãs, é muito parecida com um sapo, pois possui o corpo reforçado, a cabeça larga, a pele rugosa e o focinho curto. Distingue-se dos sapos por não possuir cristas cefálicas e da outra espécie semelhante a um sapo que ocorre na Serra do Japi (Proceratophrys boiei) por não possuir “chifres” sobre o olho. Possui porte médio (45 a $55 \mathrm{~mm}$ de CRC). Seu dorso é castanho-escuro a castanho-amarelado ou bege, com manchas escuras irregulares e linha médio-dorsal amarelada (Figura 7h). Seu lábio superior possui um padrão característico de barras escuras e largas. Possui hábito fossorial (escavador) e vive em áreas abertas do sul de Minas Gerais até o Rio Grande do Sul, sendo encontrada também no Uruguai, Paraguai, Bolívia e centro da Argentina. Esta espécie tetraplóide co-ocorre em diversas localidades com Odontophrynus cordobae, espécie diplóide morfologicamente indistinguível desta. No entanto, o nome $O$. cordobae só é aplicável às populações diplóides argentinas, faltando atribuição de um nome para as demais populações diplóides que co-ocorrem com $O$. americanus (Frost 2004).

·Physalaemus cuvieri Fitzinger, 1826

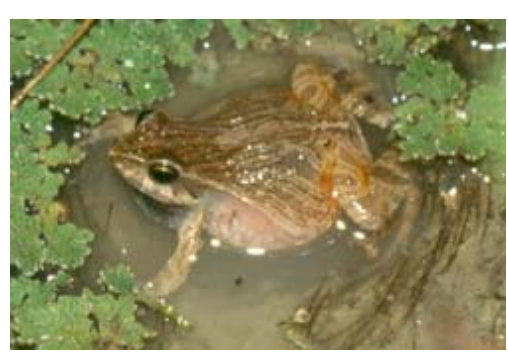

Figura 7 - Família Leptodactylidae: i) Physalaemus cuvieri.

Típica de áreas abertas de cerrado e caatinga, pode também ser encontrada em matas no Norte, Sul e Centro-Oeste do Brasil, nas províncias argentinas de Misiones e Entre Ríos, no leste do Paraguai e no departamento boliviano de Santa Cruz. É possível que haja mais de uma espécie sob este nome. É uma rã de porte pequeno a médio (20 a 35 mm de CRC). Seu dorso pode ser escuro ou com tonalidades fracas de castanho ou cinza ou mesmo verde, e com manchas ou linhas irregulares (Figura 7i). A maioria dos indivíduos possui a parte interna das coxas e a região inguinal alaranjadas a avermelhadas. Os machos apresentam a região gular enegrecida e as fêmeas possuem a região gular branca. Sua vocalização se assemelha a um latido, o que lhe dá o nome popular de rã-cachorro. Grandes coros dão a impressão de pessoas discutindo se “foi-gol-não-foi”, seu outro nome popular.

\section{·Proceratophrys boiei (Wied-Neuwied, 1824)}

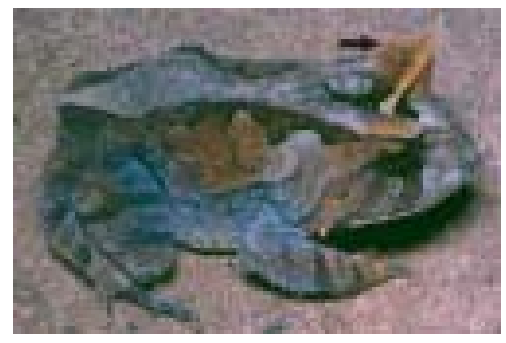

Figura 7 - Família Leptodactylidae: j) Proceratophrys boiei: note o apêndice em forma de chifre (seta) sobre os olhos.

Assim como Odontophrynus americanus, essa é uma espécie que pode alcançar um porte médio a grande (55 a 75 mm de CRC) e tem o corpo reforçado e rugoso, parecido com um sapo. Sua característica distintiva é um par de apêndices cutâneos parecidos com chifres acima do olho (Figura 7j), daí seu nome popular sapo-de-chifres. Sua coloração dorsal varia de cinzenta a parda, com o dorso ornamentado por manchas castanho-escuras. Um par de cordões dérmicos, longitudinais e sinuosos, camufla essa espécie na serapilheira, de forma que se torna difícil localizála. Sua alimentação pode incluir outros anuros, mas baseia- 
se em besouros e grilos (Giaretta et al. 1998). Ocorre de Pernambuco a Santa Catarina, podendo haver mais espécies sendo confundidas sob este nome.

Família Microhylidae

\section{-Elachistocleis cf. ovalis}

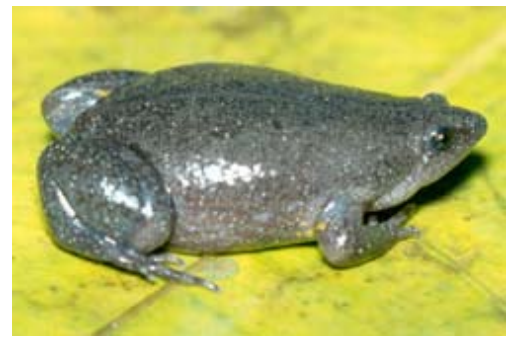

Figura 8 - Família Microhylidae: a) Elachistocleis cf. ovalis; b) Vista dorsal de Elachistocleis: note o formato ovalado do corpo e o tamanho diminuto da cabeça. A barra na figura equivale a $10 \mathrm{~mm}$.

É uma espécie de hábitos fossoriais, que deve se alimentar predominantemente dos cupins e formigas em cujos ninhos vive. Possui porte mediano (30 a $45 \mathrm{~mm}$ de CRC) e corpo ovóide, com cabeça pequena e triangular (Figura 8a e b), o que a distingue de todas as outras espécies de anuros da Serra do Japi. Seus nomes populares são rã-grilo e rã-guarda, devido a seu canto ser um apito agudo. A taxonomia dessa espécie é uma das mais obscuras, pois o nome "Elachistocleis ovalis (Schneider, 1799)” designa um complexo de espécies, mas esse nome é de difícil aplicabilidade, uma vez que sua localidade-tipo é desconhecida (Lavilla et al. 2003). Além disso, a coloração ventral de "Elachistocleis ovalis (Schneider 1799)” também é controversa, sendo apontada

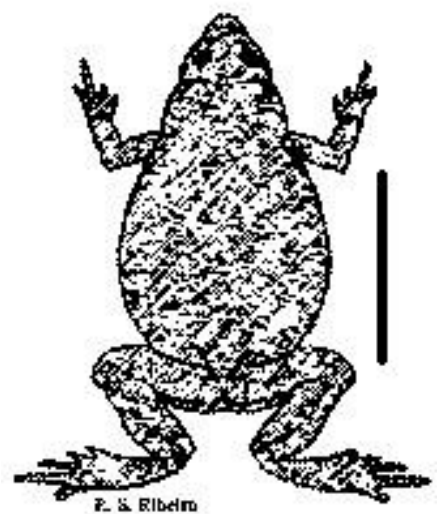

Figura 8 - Família Microhylidae: a) Elachistocleis $c f$. ovalis; b) Vista dorsal de Elachistocleis: note o formato ovalado do corpo e o tamanho diminuto da cabeça. A barra na figura equivale a $10 \mathrm{~mm}$. como amarelo uniforme por Schneider (1799) na descrição de Rana ovalis, amarelo uniforme ou pontilhado por Duméril \& Bibron (1841), quando da sinonímia de Bufo surinamensis e Oxyrhynchus bicolor com Rana ovalis, marmóreo ou pontilhado por vários autores e amarelo uniforme por outros tantos autores (cf. Lavilla et al. 2003).

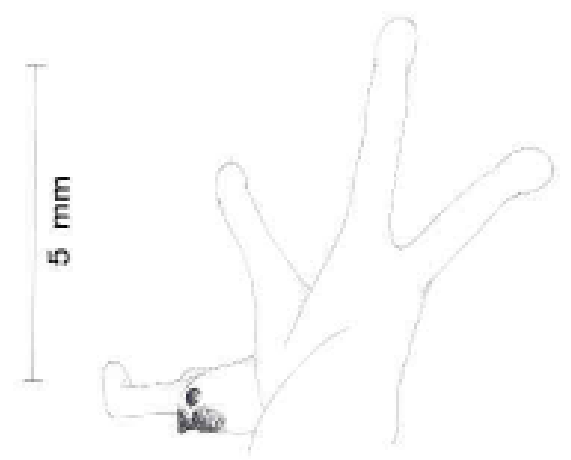

Figura 9 - Vista dorsal da mão de Crossodactylus sp. Note os espinhos negros na base do polegar (dedo I), característicos do gênero.

\section{Agradecimentos}

O Museu de História Natural da Unicamp foi fundamental para a execução deste trabalho e gostaríamos de agradecer pelo apoio e incentivo de todos que fazem o Museu. Agradecemos também aos colegas Juliana Z P. Ramos, André Antunes, MSc. L. Felipe Toledo e MSc. Luís O. M. Giasson pelas sugestões e informações. Gostaríamos também de agradecer aos autores das fotografias e gravuras que ilustram o presente trabalho, cujos créditos seguem ao fim desta seção. Este trabalho contou com o apoio da Fundação de Amparo à Pesquisa do Estado de São Paulo (FAPESP, Proc. Nº1/13341-3) e do CNPq, através do auxílio concedido ao Laboratório de Herpetologia do Departamento de Zoologia, I. B., UNESP, Rio Claro, SP. Ricardo S. Ribeiro agradece também ao CNPq pela bolsa concedida (Proc. N¹33558/2004-5).

Créditos das fotografias: Prof. Dr. Adão José Cardoso (in memorian): Figuras 4H; 7D,J. Prof. Dr. Ivan Sazima: Figuras 3; 7A. Prof. Dr. José P. Pombal Jr.: Figuras 4F. Juliana Z. P. Ramos: 4M. As demais são de autoria do Prof. Dr. Célio F. B. Haddad. A gravura a nanquim da Figura 9 é de autoria de Jaime R. Somera. As demais ilustrações a nanquim (Figuras $5 \mathrm{~A}$ e $8 \mathrm{~B}$ ) e a grafite (Figuras 5B e 6) são de autoria de Ricardo S. Ribeiro. 


\section{Referências Bibliográficas}

ANDRADE, G.V. 1987. Reprodução e vida larvária de anuros (Amphibia) em poça de área aberta na Serra do Japi. Dissertação de mestrado, Universidade Estadual de Campinas, Campinas, SP.

BALDISSERA JR., F.A., CARAMASCHI, U. \& HADDAD, C.F.B. 2004. Review of the Bufo crucifer species group, with descriptions of two new related species (Amphibia, Anura, Bufonidae). Arq. Mus. Nac., Rio de Janeiro, 62: 255 - 282.

BASTOS, R.P. \& POMBAL JR., J.P. 2001. Geographic distribution: Eleutherodactylus juipoca. Herpetol. Rev., 32: $269-270$.

BERNARDE, P.S. \& MACHADO, R.A. 1999. Hyla faber(Smith Frog). Larval canibalism. Herpetol. Rev., 30: 162-162.

CARDOSO, A.J., ANDRADE, G.V. \& HADDAD, C.F.B. 1989. Distribuição espacial em comunidades de anfíbios (Anura) no sudeste do Brasil. Rev. Bras. Biol., 49: 241 - 249.

DUMÉRIL, A.M.C. \& BIBRON, G. 1841. Erpétologie Générale ou Histoire Naturelle Complete des Reptiles. Roret, Paris 8: $\mathrm{i}-\mathrm{ii}+1-792$.

ETEROVICK, P.C. \& SAZIMA, I. 2004. Anfíbios da Serra do Cipó - Minas Gerais - Brasil = Amphibians from the Serra do Cipó. Ed. PUC - Minas, Belo Horizonte.

FAIVOVICH, J., HADDAD, C.F.B, GARCIA, P.C.A., FROST, D.R., CAMPBELL, J.A. \& WHELLER, W.C. 2005. Sistematic review of the frog family Hylidae, with special reference to Hylinae: Phylogenetic analysis and taxonomic revision. Bull. Am. Mus. Nat. Hist. 294: $1-240$.

FREITAS, M.A., SILVA, T.F.S. \& ARGÔLO,A.J.S. 2004. Geographic distribution. Hyalinobatrachium eurygnathum (Rio Glass Frog). Herpetol. Rev., 35: 281 - 281.

FROST, D.R. 2004. Amphibian Species of the World: an Online Reference. Versão 3.0 (22 de Agosto de 2004). Base de Dados Eletrônica acessível em http:// research.amnh.org/herpetology/amphibia/index.html. American Museum of Natural History, New York.

GIARETTA, A.A., SAWAYA, R.J., MACHADO, G., ARAÚJO, M.S., FACURE, K.G., DE MEDEIROS, H.F. \& NUNES, R. 1997. Diversity and abundance of litter frogs at altitudinal sites at Serra do Japi, Southeastern Brasil. Revta bras. Zool., 14: 341 - 346.

GIARETTA, A.A., ARAÚJO, M.S., MEDEIROS, H.F.\& FACURE, K.G. 1998. Food habits and ontogenetic diet shifts of the litter dwelling frog Proceratophrys boiei. Revta bras. Zool., 15: 385 - 388.

HADDAD, C.F.B. 1991. Ecologia reprodutiva de uma comunidade de anfíbios anuros na Serra do Japi, sudeste do Brasil. Tese de doutorado, Universidade Estadual de Campinas, Campinas, SP.
HADDAD, C.F.B. \& GIARETTA, A.A. 1999. Visual and Acoustic Communication in the Brazilian Torrent Frog, Hylodes asper (Anura: Leptodactylidae). Herpetologica, 55: $324-333$.

HADDAD, C.F.B. \& SAZIMA, I. 1992. Anfíbios Anuros da Serra do Japi. In História natural da Serra do Japi: ecologia e preservação de uma área florestal no Sudeste do Brasil. (L. P. C. Morellato, org.). Ed. da Unicamp / FAPESP, Campinas, p. $188-211$.

HADDAD, C.F.B., CARDOSO, A.J. \& CASTANHO, L.M. 1990. Hibridação natural entre Bufo ictericus e Bufo crucifer (Amphibia: Anura). Rev. Brasil. Biol., 50: 739 - 744.

HEYER, W.R., RAND, A.S., CRUZ, C.A.G., PEIXOTO, O.L. \& NELSON, C.E. 1990. Frogs of Boraceia. Arq. Zool., São Paulo, 31: 1-410.

JUNGFER, K.-H. 1987. Beobachtungen an Ololygon boulengeri (Cope, 1887) und anderen »Knickzehenlaubfröschen«. Herpetofauna, 9: 6-12.

KWET,A. \& DI-BERNARDO, M. 1999. Anfíbios = amphibien = amphibians. EDIPUCRS, Porto Alegre.

KWET, A. \& MIRANDA, T. 2001. Hyla prasina. First record. Herpetol. Rev., 32: 271 - 271.

LAVILLA, E.O., VAIRA, M. \& FERRARI, L. 2003. Anew species of Elachistocleis (Anura: Microhylidae) from the Andean Yungas of Argentina, with comments on the Elachistocleis ovalis - E. bicolor controversy. Amphibia-Reptilia, 24: 269-284.

MITTERMEIER, R.A., GIL, C.G. \& MITTERMEIER, C.G. (eds.), 1997. Megadiversity: Earth’s Biologically Wealthiest Nations. México, Cemex.

NAPOLI, M.F. 2000. Taxonomia, variação morfológica e distribuição geográfica das espécies do grupo de Hyla circumdata (Cope, 1870) (Amphibia, Anura, Hylidae). Tese de doutorado, Universidade Federal do Rio de Janeiro, Rio de Janeiro, RJ.

POMBAL-JR., J.P. \& HADDAD, C.F.B. 1993. Hyla luctuosa, a new treefrog from the southeastern Brazil (Amphibia, Hylidae). Herpetologica, 49: 16 - 21.

POMBAL-JR., J.P., WISTUBA, E.M. \& BORNSCHEIN, M.R. 1998. A new species of Brachycephalid (Anura) from Atlantic Rain forest. J. Herpetol., 31: 70 - 74.

RIBEIRO, L.F., ALVES, A.C.R, HADDAD, C.F.B. \& DOS REIS, S.F. 2005. Two new species of Brachycephalus Günther, 1858 from the state of Paraná, Southern Brazil (Amphibia, Anura, Brachicephalidae). Bol. Mus. Nac., N. S., Zool., Rio de Janeiro, 519: 1 - 18.

RIBEIRO, R.S., EGITO, G.T.B.T. \& HADDAD, C.F.B. 2005. Chave Interativa de Identificação: Anfíbios da Serra do Japi. Versão 1.0. Aplicativo Computacional e Base de Dados Eletrônica disponíveis em www.ib.unicamp.br/chave. 
SAZIMA, I. 1974. Experimental predation on the leaf-frog Phyllomedusa rohdei by the water snake Liophis miliaris. Journal of Herpetology, 8: 376 - 377.

SBH. 2005. Lista de espécies de anfíbios do Brasil. Sociedade Brasileira de Herpetologia (SBH). Disponível em: http:// www.sbherpetologia.org.br/checklist/anfibios.htm.

SCHNEIDER, J.G. 1799. Historiae Amphibiorum Naturalis et Literariae. Fasciculus Primus Continens Ranas, Calamitas, Bufones, Salamandras et Hydros in Genera et Species Descriptos Notisque Suis Dintinctos. Frederici Frommanni, Jena.

SOUZA, I.F., VAZ-SILVA, W., RIBEIRO, R.S., SILVA, H.L.R. \& SILVA JR., N.J. 2001. Geographic distribution. Bufo ictericus (Yellow Cururu Toad). Herpetol. Rev., 32: 269 - 269.

WOGEL, H., ABRUNHOSA, P.A. \& WEBER, L.N. 2004. The tadpole, vocalizations and visual displays of Hylodes nasus (Anura: Leptodactylidae). AmphibiaReptilia, 25: 219-227.

Título: Chave de identificação: anfíbios anuros da vertente de Jundiaí da Serra do Japi, Estado de São Paulo.

Autores: Ricardo da Silva Ribeiro, Gabriel Toselli Barbosa Tabosa do Egito \& Célio Fernando Baptista Haddad

Biota Neotropica, Vol. 5 ( number 2): 2005

http://www.biotaneotropica.org.br/v5n2/pt/ abstract?identification-key+bn03005022005

Recebido em 02/05/05 - Revisado em 24/08/05

Publicado em 10/10/05

ISSN 1676-0603

http://www.biotaneotropica.org.br 
Chave de identificação: Anfíbios Anuros da Área de Proteção Ambiental Jundiaí - Serra do Japi, SP

1 - Apenas dois dedos funcionais em cada mão e três artelhos funcionais em cada pé.

- Quatro dedos funcionais em cada mão e cinco artelhos funcionais em cada pé.

Brachycephalus ephippium (Figura 1)

2 - Corpo robusto e ovóide, cabeça pequena e triangular (Figura 8b)

Elachistocleis cf. ovalis (Figura 8a)

- Forma do corpo não como acima.

3 - Ossificações distintas sobre a cabeça (cristas cefálicas).

- Cristas cefálicas indistintas / ausentes. 6

4 - Apêndices cutâneos parecidos com "chifres" acima dos olhos.

- Região acima dos olhos lisa ou com verrugas e cristas carnosas, mas sem "chifres”.

Proceratophrys boiei (Figura 7j)

5-Sapos com 55 a 95 mm de comprimento rostro-cloacal (CRC). Maxilar superior com uma faixa estreita de coloração creme sob o olho. Glândulas parotóides (Figura 2a) com tamanho menor que 20\% do CRC. Bufo ornatus (Figura 2b)

- Sapos com 100 a 170 mm de CRC. Sem faixa creme sob o olho. Glândulas parotóides maiores que 25\% do CRC (na maioria das vezes, maiores que $30 \%)$.

Bufo ictericus (Figura 2a)

6 - Pele do dorso extremamente verrugosa e corpo robusto, semelhante a um sapo. Lábio superior com padrão característico de barras largas e escuras. Odontophrynus americanus (Figura 7h)

- Pele do dorso lisa ou um pouco granulosa, mas não muito verrugosa, e corpo mais delgado.

7 - Pelo menos seis pregas longitudinais no dorso.

Leptodactylus cf. ocellatus (Figura 7g)

- Sem pregas longitudinais no dorso.

8 - Pré-pólex (Figura 5a) presente (com ou sem espinho) ..................................................................................................9

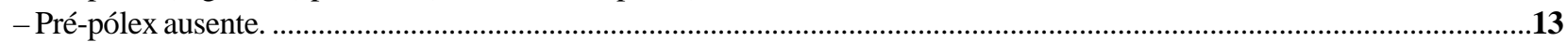

9 - Sem barras transversais no dorso das coxas.

Hypsiboas prasinus (Figura 4i)

- Com barras transversais no dorso das coxas.

10 - Membranas interdigitais presentes entre todos os dedos das mãos.

- Membranas interdigitais ausentes entre os dedos I e II das mãos (Figura 5a).

11 - Tímpano parcialmente coberto por uma prega de pele que se estende a partir do canto do olho. Pererecas adultas têm entre 50 a 60 mm de CRC.

Bokermannohyla luctuosa (Figura 4f)

- Tímpano completamente visível. A maioria dos indivíduos têm uma linha escura que vai da ponta do focinho até o meio do dorso. Pererecas adultas têm entre 70 e 105 mm de CRC.

Hypsiboas faber (Figura 4d)

12 - "Máscara” com coloração verde. Lados das pernas e dos pés com linha longitudinal escura.

- "Máscara” com coloração marrom-escura, quase negra. Face posterior das coxas com pintas amarelas

Hypsiboas bischoffi (Figura 4c)

Hypsiboas albopunctatus (Figura 4a)

13 - Pupilas verticalmente elípticas.

- Pupilas redondas ou horizontalmente elípticas.

14 - Áreas laterais do corpo e das pernas com manchas castanhas contornadas de amarelo. Pés com cor de chocolate. Pererecas com 30 a $40 \mathrm{~mm}$ de CRC.

Phasmahyla cochranae (Figura 4k)

- Áreas laterais do corpo e das pernas com manchas amarelas contornadas de azul. Pés verdes. Pererecas com 50 a $60 \mathrm{~mm}$ de CRC. .Phyllomedusa burmeisteri (Figura 4l)

15 - Saco vocal duplo. Hylodes ornatus (Figura 7f)

http://www.biotaneotropica.org.br 
16 - Presença de espinhos negros na base do polegar (Figura 9).

17 - Todos os dedos das mãos e artelhos sem dilatações terminais. ..........................................................................18

-Ao menos um dedo ou artelho com dilatação terminal.

18 - Tímpano parcialmente visível. Pele do dorso com granulações. São rãs que têm entre 10 e 25 mm de CRC.

...Eleutherodactylus juipoca (Figura 7d)

- Tímpano invisível. A maioria dos indivíduos apresenta a parte interna das coxas e a região inguinal alaranjadas a avermelhadas. São rãs que têm entre 15 e 35 mm de CRC .Physalaemus cuvieri (Figura 7i)

19 - Membranas interdigitais ausentes entre todos os dedos das mãos, ou presentes somente entre os dedos II e III

(Figura 5a). .....

- Membranas interdigitais presentes entre todos os dedos das mãos, ou ausentes somente entre os dedos I e II.

20 - Extremidades dos dedos das mãos não-dilatadas.

.Eleutherodactylus parvus (Figura 7e)

- Ao menos as extremidades dos três maiores dedos das mãos com discos.

21 - Artelho II menor que artelho III (Figura 5b). Freqüentemente possui um par de pequenas manchas negras no meio do dorso. Rãs adultas têm entre 40 e 65 mm de CRC. Eleutherodactylus binotatus (Figura 7b) - Artelho II do mesmo tamanho que artelho III. Rãs adultas têm entre 25 e 40 mm de CRC.

Eleutherodactylus guentheri (Figura 7c)

22 - Membranas interdigitais das mãos ausentes entre os dedos I e II (Figura 5a). Ventre transparente.

- Membranas interdigitais das mãos presentes entre todos os dedos. . Hyalinobatrachium eurygnathum (Figura 3)

23 - Sem barras transversais no dorso das coxas.

- Com barras transversais no dorso das coxas.

24 - Coloração verde. Tímpano parcialmente visível ou invisível. .................................................................................25

- Coloração parda. Tímpano completamente visível.

25 - Presença de uma linha pós-orbital branca.

Aplastodiscus arildae (Figura 4b)

- Linha pós-orbital ausente. Aplastodiscus leucopygius (Figura 4e)

26 - Dorso bege com mancha escura que lembra a forma de uma ampulheta. Coxas alaranjadas a avermelhadas. De 20 a $25 \mathrm{~mm}$ de CRC.

Dendropsophus minutus (Figura 4h)

- Dorso bege com pequenos pontos escuros longitudinalmente arranjados. Coxas beges. De 15 a 20 mm de CRC.

Dendropsophus sanborni (Figura 4j)

27 - Tubérculos metatarsais externos ovóides (Figura 5b).

Scinax hayii (Figura 40)

- Tubérculos metatarsais externos redondos ou indistintos.

28 - Tímpano menor do que a metade do tamanho do olho.

Scinax hiemalis (Figura 4p)

- Tímpano maior do que a metade do tamanho do olho.

29 - Tímpano do mesmo tamanho que o maior disco adesivo das mãos. Scinax eurydice (Figura 4m)

- Tímpano maior do que o maior disco adesivo das mãos.

30 - Mãos com o dedo II do menor que o dedo IV (Figura 5a). De 40 a 60 mm de CRC. Scinax fuscovarius (Figura 4n) - Mãos com o dedo II do mesmo tamanho que o dedo IV. De 20 a 30 mm de CRC. Dendropsophus microps (Figura 4g)

http://www.biotaneotropica.org.br 